\title{
Addisonian Crisis Due to Antitubercular Therapy
}

\author{
Jaivinder Yadav • Amit Kumar Satapathy • Vandana Jain
}

Received: 3 February 2015 / Accepted: 2 March 2015/Published online: 14 March 2015

(C) Dr. K C Chaudhuri Foundation 2015

To the Editor : Chronic adrenal insufficiency is characterized by deficient secretion of glucocorticoids, and often mineralocorticoids by the adrenal glands [1]. Here we are describing a 12 -y-old girl who presented with adrenal insufficiency due to adrenal tuberculosis and difficulties encountered during her management.

The girl presented to the emergency (ER) with hypotension and history of generalized hyperpigmentation for last 4 mo. She was noted to have hyponatremia and hyperkalemia, and serum cortisol was found to be low. Adrenal insufficiency was diagnosed and she was started on hydrocortisone $\left(10 \mathrm{mg} / \mathrm{m}^{2}\right)$ and fluodrocortisone $(0.1 \mathrm{mg} / \mathrm{d})$, to which good clinical and biochemical response was noted. She had a history of contact with tuberculosis. Montoux test was positive and CECT abdomen showed enlarged and necrotic adrenal glands, suggestive of adrenal tuberculosis. The child was started on antitubercular treatment (ATT). After starting ATT, the child started having weakness, lethargy and pigmentation for which she visited outpatient department repeatedly. Her BP and electrolytes were within normal limits. Steroid dose was hiked up to $30 \mathrm{mg} / \mathrm{m}^{2}$ but the response was poor. She again presented to the ER with extreme weakness and was found to have hypotension. She was admitted to investigate the cause for her symptoms; her chest radiograph, ECG and echocardiography were normal. Serum ACTH level was found to be increased $(359 \mathrm{pg} / \mathrm{ml})$. After excluding all other causes for symptoms, a diagnosis of rifampacin induced metabolism of steroids leading to corticosteroid insufficiency was made. We started her on dexamethaosne at a dose equivalent to $35 \mathrm{mg} / \mathrm{m}^{2}$ of hydro- cortisone, as it is a more potent and long-acting steroid. The child responded over the next few days; was continued on dexamethoasone for the entire duration of completion of ATT and afterwards was put on hydrocortisone $\left(12 \mathrm{mg} / \mathrm{m}^{2}\right)$ and continued to do well.

The standard management of Addison's disease is replacement of corticosteroids and mineralocorticoids [2]. Precipitation of adrenal crisis due to rifampacin induced metabolism is a rare phenomenon and only a few case reports are available $[3,4]$. In conclusion, good clinical care and frequent biochemical monitoring are required during treatment of tuberculosis in Addison's disease to adjust steroid dosages for prevention of adrenal crisis.

Conflict of Interest None.

Source of Funding None.

\section{References}

1. Addison T. On the constitutional and local effects of disease of the supra-renal capsules. London: Highley; 1866.

2. Kronenberg HM, Melmed S, Polonsky KS, Larsen PR. Adrenal cortex and endocrine hypertension. Williams textbook of endocrinology. 12th ed. Philadelphia: Saunders/Elsevier; 2011. p. 515-23.

3. Varela IC, Jackson DP, Sancho JF. Addisonian crises induced by rifampicin. Arch Bronconeumol. 2006;42:376.

4. Kyriazopoulou V, Parparousi O, Vagenakis AG. Rifampicin-induced adrenal crisis in Addisonian patients receiving corticosteroid replacement therapy. J Clin Endocrinol Metab. 1984;59:1204-6.

J. Yadav $\cdot$ A. K. Satapathy $\cdot$ V. Jain $(\bowtie)$

Division of Endocrinology, Department of Pediatrics,

All India Institute of Medical Sciences, Ansari Nagar,

New Delhi 110029, India

e-mail: drvandanajain@gmail.com 